\title{
Kan Kültürlerinden İzole Edilen Candida Türlerinin Flukonazol E Test Duyarlılıklarının CLSI Referans Mikrodilusyon Yöntemi ile Karşılaştırılması
}

\author{
Mehmet Veysel Coşkun, İclal Ağan, M. Hamidullah Uyanık, Hayrünisa Hanc1, Kemalettin Özden
}

ÖZ

Özellikle invaziv Candida enfeksiyonu etkeni izolatlar için duyarlılık testi yapılması son yıllarda antifungal ajanlara karşı artış gösteren dirençle birlikte büyük bir önem taşımaktadır. Ancak antifungal duyarlılık testi olarak "Clinical and Laboratory Standards Institute (CLSI)" tarafından standardize edilen sıvı mikrodilüsyon yönteminin (Broth Mikrodilüsyon; BMD) uygulanmasındaki zorluklar araştırmacıları rutin laboratuvarda kullanılabilecek daha pratik yöntem arayışına itmektedir. Bu çalışmanın amacı hastanemizde kan kültürlerinden izole edilen Candida izolatlarında, sistemik Candida enfeksiyonlarının tedavisinde sıklıkla kullanılan bir ajan olan flukonazole karşı duyarllığın belirlenmesinde $\mathrm{E}$ test yönteminin standart BMD yöntemi ile karşılaştırılması amaçlanmıştır. Ayrıca çalışma süreci içerisinde biriktirilen izolatların tiplendirilmesi ile hastanemizde en sık kandidemi etkeni olan Candida türlerinin oranı da belirlenmiştir.

Çalışmaya Atatürk Üniversitesi Hastanesi Tibbi Mikrobiyoloji Laboratuvarı'na Nisan 2012-Aralık 2015 tarihleri arasında çeşitli kliniklerden gönderilen kan kültürlerinden (BACTEC 9000 Sistemi; Becton Dickinson ${ }^{*}$ ) izole edilen 74 Candida izolatı (49 adet C. albicans, 15 adet C. parapsilosis, 6 adet C. tropicalis, 4 adet C. glabrata) dahil edilmiştir. Candida türlerini tanımlamak için kromojenik agar ve VITEK 2 otomatize sisteminin (BioMerieux ${ }^{\circ}$,Fransa) ilgili tiplendirme kartları kullanılmış, gerekli olması durumunda suşların mısır unlu Tween 80 agar besiyerinde morfolojik görünümlerine bakılmıştır. Candida türlerinin flukonazol duyarlılıkları CLSI tarafından tanımlanan standart BMD yöntemi ve E test yöntemi ile incelenmiştir.
Çalışmaya dahil edilen 74 izolatın 49'nun (\%66.2) albicans ve 25 'inin ise (\%33.8) albicans dışı türler olduğu görülmüştür. En sık izole edilen albicans dışı türün C.parapsilosis (\%20.2) olduğu tespit edilmiştir. MIK değerlerine göre C.albicans ve C.glabrata izolatlarında her iki yöntemle de flukonazol direncine rastlanmamıștır. Bununla birlikte 15 C.parapsilosis izolatının 2'si her iki yöntemle flokonazole dirençli olarak gözlenirken; 6 C.tropicalis izolatından 2'si E test yöntemi ile dirençli olarak yorumlanmıştır. BMD yöntemi ile ise aynı C.tropicalis izolatlarından biri duyarlı diğeri ise doz bağımlı duyarlı (S-DD) olarak tespit edildi. Buna göre Candida türlerinde toplam direnç oranı $\mathrm{E}$ test yöntemi ile \%5.4 iken bu oran BMD yönteminde \%2.7 olarak belirlenmiş̧tir. C.tropicalis türlerinde $\mathrm{E}$ test yöntemi ile dirençli BMD yöntemi ile duyarlı olan sonuç "büyük hata" (ME); E test yöntemi ile dirençli BMD yöntemi ile doz bağımlı duyarlı (S-DD) olan sonuç ise "küçük hata" (mE) şeklinde değerlendirilmiştir. Candida türlerinde E test ile flukonazol duyarlılığı bakılmasında "çok büyük hata"ya (VME) rastlanmamış, toplam uyum (EA) \%85.1 olarak hesaplanmıştır. Elde ettiğimiz veriler $\mathrm{E}$ test yönteminin rutin laboratuvarda Candida türleri için alternatif bir antifungal duyarlllık testi olarak kullanılabileceğini işaret etmektedir. Bununla birlikte her ne kadar E test yöntemi, BMD yöntemine göre kolay kullanıma sahip olması, tekrarlanabilirliğinin yüksek olması avantajlarını taşısa da, antifungal duyarlılı testi olarak kullanılırken uygulama ve yorumlama aşamalarında dikkat ve deneyim gerektirmektedir.

Anahtar sözcükler: Candida, E-test, flukonazol, mikrodilüsyon testi
Mehmet Veysel Coşkun, İclal Ağan, M. Hamidullah Uyanık

Atatürk Üniversitesi Tip Fakültesi, Mikrobiyoloji ve Klinik Mikrobiyoloji Anabilim Dal, Erzurum

Hayrünisa Hancı

Atatürk Üniversitesi Eczacıllk Fakültesi Farmasötik Mikrobiyoloji Ana Bilim Dal, Erzurum

Kemalettin Özden

Atatürk Üniversitesi Tip Fakültesi Enfeksiyon Hastalıları Ana Bilim Dalı, Erzurum

\section{Corresponding Author:}

Mehmet Veysel Coşkun

e-posta: coskun.veysel@gmail.com

Tel. (0442) 2316932
Submitted / Gönderilme: 30.10.2016

Accepted / Kabul: $\quad 06.01 .2017$

Revised / Düzeltme: 05.01.2017

\section{Giriş}

İnvaziv Candida enfeksiyonları yüksek mortalite ve morbidite oranları ile birlikte hastanede yatış süresini ve tedavi maliyetlerini arttırması nedeniyle tüm dünyada halen önemli bir sağlık problemi olarak görülmektedir (1). Kandidemi olgularının insidansı maligniteler, immünsüpresif hastalıklar veya tedaviler, geniş spektrumlu antibiyotik ve kortikosteroid kullanılması, agresif kemoterapiler ve bazı major cerrahi prosedürler ile artmaktadır $(2,3)$. Centers for Diseases Control and Prevention (CDC) ve The National Healthcare Safety Network (NHSN) verilerine göre Candida türleri Amerika ve Avrupa'da sepsis etkenleri arasında dördüncü sırada yer almaktadır (2, 4-6). Bununla birlikte antifungal ajanlara karşı artmakta olan direncin varlığı antifungal duyarlılık testlerinin 
önemini artırmaktadır. Her ne kadar antifungal ajan seçimi öncelikle fungal identifikasyona dayansa da özellikle invaziv Candida enfeksiyonlarının tedavisinde antifungal duyarlılık testleri (AFDT) doğru antifungal ajanın seçimi için önemli bir rol oynamaktadır $(7,8)$.

Clinical and Laboratory Standards Institute (CLSI) Candida türlerinde flukonazol in vitro duyarlılığını test etmek için broth mikrodilüsyon yöntemini (BMD) yillar önce standardize etmiştir (9). Bununla birlikte BMD yönteminin zaman alıcı olması ve uygulanmasinda bazı zorluklarla karşılaşılmasının yanısıra rutin kullanıma uygun olmaması laboratuvarlarda antifungal duyarlılık tayininde rutin kullanılabilecek pratik yöntem arayışına neden olmaktadır. Bunların içerisinde rutin uygulamada standardize edilmemiş olsa da E test yöntemi, pratik kullanıma sahip olması ve tekrarlanabilirliğinin yüksek olması avantajları ile antifungal duyarlılık tayininde önemli bir alternatif olarak karşımıza çıkmaktadır (10).

Bu çalışma ile hastanemizde kan kültürlerinden izole edilen Candida izolatlarında, sistemik Candida enfeksiyonlarının tedavisinde sıklıkla kullanılan bir ajan olan flukonazole karşı duyarlılığın belirlenmesinde $\mathrm{E}$ test yönteminin standart BMD yöntemi ile karşılaştırılması amaçlanmıştır. Ayrıca çalışma süreci içerisinde laboratuvarımıza gönderilen kan kültürlerinden izole edilen Candida'ların tiplendirilmesi ile hastanemizde en sık kandidemi etkeni olan Candida türlerinin oranı da belirlenmiştir.

\section{Gereç ve Yöntem}

Candida kökenleri: Çalışmaya Atatürk Üniversitesi Hastanesi Tibbi Mikrobiyoloji Laboratuvarı'na Nisan 2012-Aralık 2015 tarihleri arasında çeşitli kliniklerden gönderilen kan kültürlerinden (BACTEC 9000 Sistemi; Becton Dickinson) ${ }^{\circledR}$ izole edilen 74 Candida izolatı (49 adet C.albicans, 15 adet C.parapsilosis, 6 adet C.tropicalis, 4 adet C.glabrata) dahil edilmiştir. İzole edilen Candida türlerini tanımlamak için kromojenik agar ve VITEK 2 otomatize sisteminin (BioMerieux ${ }^{\circledast}$,Fransa) ilgili tiplendirme kartları kullanılmış, gerekli olması durumunda mısır unlu Tween 80 agar besiyerindeki morfolojik görünümlerine bakılmıştır. Tiplendirilen suşlar çalışmanın planlandığı tarihe kadar stok besiyeri süspansiyonları hazırlanarak $-80{ }^{\circ} \mathrm{C}$ 'de saklanmıştır. Duyarlılık testi öncesinde suşlar oda sıcaklığında çözdürüldükten sonra optimal üreme ve saf kültür elde edilmesi amacı ile Saboraud Dekstroz Agar'da (Oxoid, İngiltere) iki kez pasajlanmıştır. Candida türlerinin flukonazol duyarlılıkları BMD ve E test yöntemleri ile incelenmiştir.
Çalışmada C.krusei ATCC 6258 ve C.parapsilosis ATCC 22019 suşları kontrol suşu olarak kullanılmıştır.

Sıvı Mikrodilüsyon Yöntemi: CLSI M27-A3 önerilerine göre L-glutaminli, bikarbonatsı,, RPMI 1640 (Sigma Chemical Co, St Louis, Mo, USA) kullanılarak referans mikrodilüsyon yöntemi uygulanmıştır (11). Bu besiyeri \%2 dekstroz ilave edilip $0.165 \mathrm{M}$ morfolin-propan-sülfonik asit (MOPS; Sigma) ile pH'1 7 olarak ayarlandıktan sonra BMD testinde kullanılmıştır. Bu yöntem doğrultusunda önce flukonazol toz etken maddesi (Pfizer) BMD testinde kullanılacak son konsantrasyonunun 10 katı olacak şekilde çözülüp stok solüsyonu hazırlanmıştır. Daha sonra \%2 dekstroz ilave edilip MOPS ile tamponlanmış L-glutaminli, bikarbonatsı, RPMI 1640 ile dilüe edilip steril, U tabanl,, 96 kuyucuklu mikroplaklara her kuyucukta $100 \mu \mathrm{l}$ besiyeriilaç çözeltisi olacak şekilde iki kat azalan seri dilüsyonları hazırlanmıştır. Otomatik ölçüm cihazı ile \% 0.85 sodyum klorür içerisinde $0.5 \mathrm{McFarland}$ süspansiyonları hazırlanan suşlar CLSI M27-A3 standartlarına uygun olarak dilüe edilip sadece sondan bir önceki kuyucuk boş bırakılacak şekilde tüm kuyucuklara 100'er $\mu \mathrm{l}$ dağıtılmıştır (11). Sondan bir önceki kuyucuk sterilite kontrol kuyucuğu ve en sondaki kuyucuk üreme kontrol kuyucuğu olarak ayrılmıştır. Böylece son flukonazol konsantrasyonunun 64 $\mu \mathrm{g} / \mathrm{mL}-0.125 \mu \mathrm{g} / \mathrm{mL}$ aralığında olması sağlanmıştır. Plaklar 24 saatlik inkübasyondan sonra ön değerlendirmeye alınmış üreme olmaması durumunda 48 saatlik inkübasyonun ardından üç farklı araştırmacı tarafından çıplak gözle değerlendirilmiştir. Üreme kontrol kuyucuğuna göre \%50 ve daha az üreme olan en küçük ilaç konsantrasyonuna sahip kuyucuk MİK değeri olarak kaydedilmiştir. Araştırmacılar tarafından ortak MİK değeri belirlenemeyen suşlar yeniden çalışılmıştır.

E test Yöntemi: Bu test için flukonazol E test (BioMerieux ${ }^{\circledR}$, Fransa) stripleri kullanılmıştır. Üretici firmanın önerileri doğrultusunda \%2 glikoz ve \%1.5 agar içeren RPMI 1640 (Sigma Chemical Co, St Louis, Mo, USA) besiyerine \% 0.85 sodyum klorürde $0.5 \mathrm{McF}$ arland standard bulanıklı̆̆ına göre süspansiyonları hazırlanmış Candida izolatları eküvyon ile agar yüzeylerine inokule edilmiştir. Agar plakların yüzeyleri kuruduktan sonra flukonazol $(0.016 \mu \mathrm{g} / \mathrm{mL}-256 \mu \mathrm{g} / \mathrm{mL})$ içeren E-test şeritleri yerleştirilmiştir. Daha sonra plaklar $37^{\circ} \mathrm{C}$ 'de 24 saat, eğer yetersiz üreme varsa 48 saat inkübe edilmiş ve inkübasyon sonrasında $\mathrm{E}$ test şeridinde \%80 üreme inhibisyonu sağlayan en küçük değer MİK $(\mu \mathrm{g} / \mathrm{mL})$ değeri olarak belirlenmiştir.

Değerlendirme: Flukonazol MİK değerleri CLSI M27-S4 sınır değerlerine göre değerlendirilmiş ve C.albicans, C.parapsilosis, C. tropicalis için MİK değeri $\leq 2 \mu \mathrm{g} / \mathrm{mL}, 4$ 
$\mu \mathrm{g} / \mathrm{mL}$ ve $\geq 8 \mu \mathrm{g} / \mathrm{mL}$ olan izolatlar sirasiyla duyarlı (S), doza bağlı duyarlı (S-DD) ve dirençli (R) olarak yorumlanırken; C.glabrata için MİK değeri $\leq 32 \mu \mathrm{g} / \mathrm{mL}$ olan suşlar SS-D ve $\geq 64 \mu \mathrm{g} / \mathrm{mL}$ olan suşlar R olarak yorumlanmıştır (12). E test ve BMD yöntemlerinden elde edilen MİK değerleri arasında \pm 2 kat dilüsyona kadar fark olması yöntemler arası mutlak uyum (EA) olarak değerlendirilmiştir. MİK değerleri karşılaştırılırken 24 saatlik inkübasyon sonrası elde edilen sonuçlar dikkate alınmıştır. Daha geniş MİK aralığına sahip E-testten elde edilen MİK değerleri, karşılaştırmanın kolay olması amacıyla, BMD ile elde edilen MİK değerinin en yakın bir üst konsantrasyon değerine eşitlenmiştir. Duyarlılık sonuçları farklı olan suşlar için VME (Very Major Error), ME (Major Error) ve mE (minor error) belirlenmiştir. Bunun için E-test ile duyarlı ancak BMD ile dirençli bulunan suşlar için VME; E-test ile dirençli ancak BMD ile duyarlı bulunan suşlar için ME; bir suşun bir yöntemle dirençli veya duyarlı bulunup diğer yöntemle doza bağlı duyarlı bulunması için de $\mathrm{mE}$ değerlendirmesi yapilmıştır .

\section{Bulgular}

Çalışmaya dahil edilen 74 Candida izolatı hastanemizdeki 16 farklı klinikte yatmakta olan hastalara ait kan kültürlerinden izole edilen suşlardır. Bunların büyük çoğunluğunu Anestezi ve Reanimasyon Yoğun Bakım (\%27), Dahiliye Yoğun Bakım (\%14.8), Dahiliye Hematoloji (\%10.8), Pediatri Yoğun Bakım (\%9.5), Medikal Onkoloji (\%8.1) ve Nöroloji Yoğun Bakım (\%6.8) kliniklerinde yatmakta olan hastalar oluşturmaktadır. İzole edilen Candida türlerinin servislere göre dağılımı Tablo l'de özetlenmiştir.

İzole edilen suşlar içerisinde albicans türlerinin (\%66.2) albicans dışı türlerden (\%33.8) daha fazla olduğu görüldü. En sık izole edilen albicans dışı tür C.parapsilosis (\%20.2) idi.

Çalışmamızda E-test ve standart BMD yöntemleri ile elde edilen $\mathrm{MIK}_{50}, \mathrm{MIK}_{90}$ ve MİK aralıklarının Candida türlerine göre dağılımı Tablo 2'de gösterilmiştir. Tablo 2'de görüldüğü gibi gibi en düşük MİK değeri C.albicans türlerinde saptanırken (MİK:0.094 $\mu \mathrm{g} / \mathrm{ml}$ ) en yüksek MİK değerleri C.parapsilosis ve C.tropicalis türlerinde (MİK:16 $\mu \mathrm{g} / \mathrm{ml}$ ) belirlenmiştir.

Tablo 1. Candida türlerinin izole edildikleri servislere göre dağılımı ( $n=74)$.

\begin{tabular}{lccccc}
\hline Servisler & C.albicans & C.parapsilosis & C.tropicalis & C.glabrata & Toplam \\
\hline Anestezi YB & 11 & 5 & 4 & - & 20 \\
Dahiliye YB & 9 & 1 & - & 1 & 11 \\
Dahiliye Hematoloji & 5 & 2 & - & 1 & 8 \\
Genel Pediatri YB & 6 & - & 1 & - & 7 \\
Medical Onkoloji & 6 & - & - & - & 6 \\
Nöroloji YB & 3 & 2 & - & - & 5 \\
Organ Nakli & 2 & - & 1 & 1 & 4 \\
Pediatrik Enfeksiyon & 1 & 2 & - & - & 3 \\
Yeni Doğan YB & 1 & 1 & - & - & 2 \\
Enfeksiyon Hastalikları & 2 & - & - & - & 2 \\
Kardiyoloji YB & 1 & - & - & 1 & 2 \\
Pediatrik Hematoloji & 1 & 1 & - & - & 2 \\
Beyin Cerrahi YB & 1 & - & - & - & 1 \\
Yanik Tedavi Ünitesi & - & 1 & 6 & - & 7 \\
\hline Toplam & 49 & 15 & & & \\
\hline
\end{tabular}

*YB: Yoğun Bakım

Tablo 2. Flukonazol için Candida türlerine Karşı E-test ve BMD Yöntemi ile Elde Edilen MİK ${ }_{50}$, MİK ${ }_{90}$ ve MİK aralı̆̆ Sonuçları $(n=74)$

\begin{tabular}{lccccccc} 
Tür $(\mathbf{n})$ & \multicolumn{2}{c}{ MİK $_{50}$} & \multicolumn{2}{c}{ MİK $_{90}$} & \multicolumn{2}{c}{ MİK aralı̆̆ } & Toplam uyum \\
\hline & E test & BMD & E test & BMD & E test & BMD & \\
\hline C.albicans (49) & 0.25 & 0.125 & 0.38 & 0.25 & $0.094-1.5$ & $0.125-0.5$ & $(47) \% 95.9$ \\
C.parapsilosis (15) & 0.38 & 0.25 & 8 & 8 & $0.125-16$ & $0.125-16$ & $(14) \% 93.3$ \\
C.tropicalis (6) & 0.38 & 0.5 & 12 & 2 & $0.19-16$ & $0.125-4$ & $(1) \% 16.6$ \\
C.glabrata (4) & - & - & - & - & $0.38-6$ & $0.125-1$ & $(1) \% 25$ \\
Bütün izolatlar (74) & 0.25 & 0.125 & 2 & 1 & $0.094-16$ & $0.125-16$ & $(63) \% 85.1$ \\
\hline
\end{tabular}


MİK değerleri CLSI M27-S4 sınır değerlerine göre yorumlandığında iki C.parapsilosis izolatı her iki yöntemle flukonazole dirençli olarak gözlenirken (E test ve BMD MİK: $16 \mu \mathrm{g} / \mathrm{mL})$; iki C.tropicalis izolatı E test ile dirençli olarak yorumlanmış (E test MİK: $12 \mu \mathrm{g} / \mathrm{mL}-16 \mu \mathrm{g} / \mathrm{mL}$ ), BMD ile ise aynı izolatlardan biri duyarlı (BMD MIK: 2) diğeri ise doz bağımlı duyarlı (BMD MİK: 4) olarak tespit edilmiştir. Buna göre Candida türlerinde flukonazole toplam direnç oranı E test yöntemi ile \%5.4 iken bu oran BMD yönteminde \%2.7 olarak belirlenmiştir. C.tropicalis türlerinde $\mathrm{E}$ test yöntemi ile dirençli BMD yöntemi ile duyarlı olan sonuç "büyük hata" (ME); E test yöntemi ile dirençli BMD yöntemi ile doz bağımlı duyarlı olan sonuç ise "küçük hata" (mE) şeklinde değerlendirilmiştir. Candida türlerinde E test ile flukonazol duyarlılığı bakılmasında "çok büyük hata”ya (VME) rastlanmamış, toplam uyum (EA) \%85.1 olarak hesaplanmıştır.

\section{Tartışma}

Azoller diğer antifungal ajanlara göre daha az toksik etkiye sahip olmaları avantajı ile fungal enfeksiyonların tedavisinde sıklıkla kullanılmaktadır. Ancak bu durum son zamanlarda fungal ajanlarda azole karşı direnç artışına neden olmuş ve enfeksiyon etkeni fungal izolatlar için AFDT’nin önemini arttırmıştır. Ancak AFDT olarak CLSI tarafından standardize edilen BMD yöntemi zaman alıcı olmakla birlikte değerlendirme zorluğu içeren bir yöntemdir. $\mathrm{Bu}$ sebeple araştırmacılar rutin laboratuvarda AFDT olarak kullanılabilecek daha pratik ve güvenilir yöntem arayışı içerisindedir. $\mathrm{Bu}$ amaçla planlanan çalışmamızda mukokutanöz ve sistemik Candida enfeksiyonlarının tedavisinde sıklıkla kullanılan bir ajan olan flukonazole duyarlılığın saptanmasinda $\mathrm{E}$ test ve BMD yöntemleri karşılaştırılmış ve elde edilen sonuçlarla E test yönteminin etkinliği araştırılmıştır. Ayrıca çalışma süreci içerisinde biriktirilen izolatların dağılımı ile hastanemizde en sık kandidemi etkeni olan Candida türleri de belirlenmiştir.

Çalışmamızda kan kültürlerinden C.albicans'ın (\%66.2) albicans dışı Candida türlerinden (\%33.8) daha sı izole edildiği görülmüştür. İzolasyon oranları ülkemizde daha önce yapılmış çalışmalardaki sonuçlarla benzerlik göstermektedir (13-15). Ancak hem ülkemizde hem yurt dışında kan kültürlerinden albicans dışı Candida türlerinin C.albicans'tan daha sık izole edildiğini gösteren çalışmalar bulunmaktadır(16-20).
Çalışmamızda en sık izole edilen albicans dışı Candida türünün C.parapsilosis (\%20.2) olduğu gözlenmiştir. Bu sonuç ülkemizde yapılan çeşitli çalışmalarla uyumlu olmakla birlikte $(13,18,21)$ C.tropicalis ve C.glabrata'yı da kan kültürlerinden en sık izole edilen albicans dışı Candida türü olarak belirten çalışmalar da bulunmaktadır (16, 17, 22). Hem C.albicans-albicans dışı Candida oranları arasında hem de en sık izole edilen albicans dışı Candida türleri arasında gözlenen değişkenliğin bölgesel farklılıklar ile birlikte ampirik antifungal kullanımına ve çalışmaya dahil edilen suş sayısına bağlı olduğunu düşünmekteyiz.

Elde ettiğimiz MİK değerlerine göre çalışmamızda Candida türlerinde toplam direnç oranı E test yöntemi ile \%5.4 ve BMD yöntemi ile \%2.7 olarak belirlenmiştir. Ülkemizde yapılan birçok çalışmada da flukonazole karşı direnç oranlarının düşük olduğu belirtilmiştir $(13,14,18,21)$.

AFDT yapılırken MİK değerlerinin 24 saatlik ve 48 saatlik inkübasyon süresine göre değişim göstermesi "trailing phenomen" olarak adlandirılmaktadır (23). Candida türlerinde azol duyarlılığı bakılırken sıklıkla karşılaşılan bu durum benzeri çalışmalardan elde edilen sonuç farklılığına yansımaktadır. Bazı araştırmacılar hem 24 saat sonraki hem de 48 saat sonraki değerlendirme sonuçlarını dikkate almışken bazıları sadece 24 saat sonraki değerlendirme sonuçlarını belirtmişlerdir $(13,24,25)$. Yapılan birtakım çalışmalarda özellikle flukonazol için 24 saatlik inkübasyon sonrası yapılan değerlendirmenin daha uygun olduğu belirtilmiştir (26). Bizim çalışmamızda da 24 saatlik inkübasyon sonrası yapılan değerlendirme dikkate alınmıştır.

Candida türlerinde AFDT yapılmasında E test yönteminin etkinliği konusunda yurt dışında birçok çalışma yapılmışken ülkemizde bu konuda yapılmış çalışma sayısı sınırlıdır (13, 27-31). Bunların içerisinde 1997 yılındada Arikan ve ark (27) tarafından yapılan bir çalışmada 101 Candida suşunda flukonazol ve amfoterisin B için AFDT yapılmasında E test yöntemi ile kolorimetrik dilüsyon yöntemi, standart broth makrodilüsyon yöntemi ile karşılaştırılmış E test yönteminin toplam uyumu 24 saatlik ve 48 saatlik değerlendirme sonrası sırasıyla \%84 ve \%87 olarak tespit edilmiştir. Koç ve ark $(28,29) 1998$ yılında 60 ve 2000 yılında 98 Candida suşu ileyaptıkları iki farklı çalışmada 24 saatlik değerlendirme sonrası BMD yöntemi ile karşılaştırıldı̆̆ında $\mathrm{E}$ test yönteminin flukonazol duyarlılı̆̆ bakılmasındaki toplam uyumunu sırasıyla \%85 ve \%79.4 olarak belirlemişlerdir. 2010 yılında bu amaçla yapılmış iki çalışma bulunmaktadır. Keçeli ve ark (13) 46 Candida suşunda flukonazol ile birlikte 4 farklı antifungal için E testin etkinliğini BMD yöntemi 
ile kıyaslamış ve flukonazol için E test yönteminin toplam uyumunu 24 saatlik değerlendirme sonrası \%80.4 olarak bulmuşken Evci ve ark (31) bu oranı 86 Candida suşu için 24 saatin sonundaki değerlendirme ile $\% 85.5,48$ saatin sonundaki değerlendirme ile \%73.3 olarak gözlemişlerdir. Bu sonuçlara göre bizim çalışmamız dahil ülkemizde yapılmış benzeri çalışmalardaki Candida türlerinde flukonazol için antifungal duyarlılık bakılmasında $\mathrm{E}$ test yönteminin toplam uyum oranı \%79.4-\%94.1 aralığında seyretmektedir.

Yurt dışında yapılan benzeri çalışmalarda da E test yönteminin Candida suşlarında AFDT olarak güvenirliği hem 24 saatlik hem de 48 saatlik değerlendirmeler sonrasında yüksek olarak bulunmuştur (toplam uyum: \%90-\%99.5)(10, 24, 25, 32-34).

Sonuç olarak çalışmamızdan elde ettiğimiz verilere göre hastanemizin çeşitli kliniklerinde yatmakta olan hastaların kan kültürlerinden izole edilen Candida suşları için flukonazol direnç oranının düşük olduğu gözlenmiştir. Bu suşlar içerisinde en sık C.albicans türü izole edilirken en sık izole edilen albicans dışı Candida türü C.parapsilosis'tir. Candida türlerinde $\mathrm{E}$ test yöntemi ile flukonazol duyarlılığ bakılmasında VME rastlanmazken; bir C.tropicalis suşu için ME ve başka bir C.tropicalis suşu için $\mathrm{mE}$ tespit edilmiş, E test yönteminin toplam uyumu \%85.1 olarak hesaplanmıştır. Elde ettiğimiz veriler $\mathrm{E}$ test yönteminin rutin laboratuvarda Candida türleri için alternatif bir AFDT olarak kullanılabileceğini işaret etmektedir. Bununla birlikte her ne kadar E test yöntemi BMD yöntemine göre kolay kullanıma sahip olması, tekrarlanabilirliğinin yüksek olması avantajları taşısa da, AFDT olarak kullanılırken uygulama ve yorumlama aşamalarında dikkat ve deneyim gerektirmektedir. Ayrıca çalışmamız suş sayısı ve antifungal çeşitliliği açısından sınırlılık taşıdığından sonuçlarımız daha çok sayıda suşla ve farklı antifungal ajanlarla yapılacak geniş kapsamlı çalışmalarla desteklenmelidir.
Comparison of the E test with the CLSI Broth Microdilution Reference Method for Testing Fluconazole against Candida spp. Isolated from Blood Cultures

Abstract
Increased resistance against antifungal agents recently shows the
importance of antifungal susceptibility testing especially to Candida
spp. isolated from invasive infections. Although the Broth Microdilution
(BMD) method has been standardized as an antifungal susceptibility
testing by "Clinical and Laboratory Standards Institute (CLSI)",
difficulties in the practice of the this method pushed the researchers to
seek more practical methods that can be used in routine laboratories.
The aim of this study was to compare E-test method with standard
BMD method for antifungal susceptibility testing of Candida spp.
isolated from blood cultures in our hospital, against fluconazole which
is commonly used in the treatment of systemic Candida infections. In
addition by the distribution of the accumulated isolates in the process
of the study, the most common species of Candida causes Candidemia
in our hospital were determined.
74 Candida strains ( 49 C. albicans, 15 C.parapsilosis, 6 C.tropicalis, 4 C.
glabrata) isolated from blood cultures (BACTEC 9000 System, Becton
Dickinson ${ }^{\circ}$ ) sent from various clinics to Ataturk University Hospital
Medical Microbiology Laboratory between April 2012 -December 2015
were included in the study. Chromogenic agar, automated VITEK
2 system (BioMerieux', France) and if necessary the morphological
appearance on Corn Meal Agar with Tween 80 were used to identify
Candida spp. Fluconazole susceptibility of Candida species were determined by standard BMD method defined by CLSI and E test method.

While 49 of the 74 isolated strains (66.2\%) were albicans, 25 of them (33.8\%) were found to be non-albicans species. The most frequently non-albicans species were C.parapsilosis (20.2\%). According to the MIC values, no fluconazole resistance was interpreted for C.albicans and C.glabrata by both methods. However, 2 of 15 C.parapsilosis strains were interpreted as resistant to floconazole with both methods and 2 of 6 C.tropicalis strains were interpreted as resistant with E test method. While one of the same C.tropicalis strains was interpreted as susceptible, the other one was interpreted as susceptible-dose dependence (S-DD) with BMD method. According to these findings the total resistance rate of Candida species was $5.4 \%$ by E test method while it was determined as $2.7 \%$ in BMD method. In C.tropicalis species the result which was resistance by $\mathrm{E}$ test method and sensistive by BMD method was evaluated as "major error" (ME); the result which was resistance by $\mathrm{E}$ test method and susceptible-dose dependence (S-DD) by BMD method was evaluated as "minor error" (mE). Any "very major error" (VME) was not found and the total agreement (EA) was calculated as $85.1 \%$ in the study.

According to our results that can be suggested E test method can be used as an alternative antifungal susceptibility test in routine laboratory. However, although the E test method is easy to use and has high reproducibility advantage compared with the BMD method, it requires attention and experience in the application and interpretation phases of antifungal susceptibility testing.

Keywords: Broth microdilution, Candida, E-test, fluconazole 


\section{Kaynaklar}

1. Bassetti M, Righi E, Costa A, Fasce R, Molinari MP, Rosso R, Viscoli C. Epidemiological trends in nosocomial candidemia in intensive care. BMC Infect Dis 2006; 6: 1.

2. Wisplinghoff H, Bischoff T, Tallent SM, Seifert H, Wenzel RP,Edmond MB. Nosocomial bloodstream infections in US hospitals: analysis of 24,179 cases from a prospective nationwide surveillance study. Clin Infect Dis 2004; 39: 30917.

3. Yapar N. Epidemiology and risk factors for invasive candidiasis. Ther Clin Risk Manag 2014; 10: 95-105.

4. Pfaller MA, Diekema DJ. Epidemiology of invasive candidiasis: a persistent public health problem. Clin Microbiol Rev 2007; 20: 133-63.

5. Sievert DM, Rick P, Edwards JR, Schneider A, Patel J, Srinivasan A, Fridkin S. National Healthcare Safety Network (NHSN) Team and Participating NHSN Facilities. Antimicrobialresistant pathogens associated with healthcare-associated infections: summary of data reported to the National Healthcare Safety Network at the Centers for Disease Control and Prevention, 2009-2010. Infect Control Hosp Epidemiol 2013; 34: 1-14.

6. Tortorano AM, Peman J, Bernhardt H, Klingspor L, Kibbler CC, Faure O, Grillot R. Epidemiology of candidaemia in Europe: Results of 28-month European Confederation of Medical Mycology (ECMM) hospital-based surveillance study. Eur J CliN MicrobioL Infect Dis 2004; 23: 317-22.

7. Hospenthal DR, Murray CK, Rinaldi MG. The role of antifungal susceptibility testing in the therapy of candidiasis. Diagn Microbiol Infect Dis 2004; 48: 153-60.

8. Pappas PG, Kauffman CA, Andes DR, Clancy CJ, Marr KA, Ostrosky-Zeichner L, Zaoutis TE. Clinical practice guideline for the management of candidiasis: 2016 update by the Infectious Diseases Society of America. Clin Infect Dis 2015; 4: 933.

9. National Committee for Clinical Laboratory Standards (NCCLS). Performance standards for antimicrobial disc susceptibility testing; Approved Standards. NCCLS, USA. 2002.

10. Bourgeois N, Dehandschoewercker L, Bertout S, Bousquet PJ, Rispail P, Lachaud L. Antifungal susceptibility of 205 Candida spp. isolated primarily during invasive candidiasis and comparison of the Vitek 2 system with the CLSI broth microdilution and E test methods. J Clin Microbiol 2010; 48: 154-61.

11. Clinical and Laboratory Standards Institute (CLSI). Reference Method for Broth Dilution Antifungal Susceptibility Testing of Yeasts; Approved Standard M27-A3. CLSI, Wayne PA, USA. 2008.

12. Clinical and Laboratory Standards Institute (CLSI). Reference Method for Broth Dilution Antifungal Susceptbility Testing of Yeasts; $4^{\text {th }}$ Informational Supplement, M27-S4. CLSI, Wayne PA, USA. 2012.

13. Keçeli Özcan S, Mutlu B, Dündar D, Willke A. Kan kültürleinden izole edilen Candida spp. suşlarının antifungal ilaçlara karşı duyarlılıklarının belirlenmesinde buyyon mikrodilüsyon ile $\mathrm{E}$ test yöntemlerinin karşılaştırılması. Mikrobiyol Bul 2010; 44: 263-71.
14. Karakoç E, Yazgı H, Aktaş AE, Uyanık MH. Çeşitli Candida türlerinin iki farklı triazol duyarlılıklarının mikrodilüsyon yöntemi ile araştırılması. Eurasian J Med 2007; 39: 177.

15. Alışkan HE, Bozkırlı ED, Çolakoğlu Ş, Demirbilek M. Hastanemizde üç yıllık süreçte kan kültürlerinden izole edilen Candida albicans ve non-albicans Candida türlerinin etken olduğu kandidemilerdeki risk faktörlerinin irdelenmesi. Türk Hijyen ve Deneysel Biyoloji Derg 2015; 73: 15-24.

16. Şahiner F, Ergünay K, Özyurt $M$, Ardıç N, Hoşbul T, Haznedaroğlu T. Hastane enfeksiyonu etkeni olarak izole edilen Candida suşlarının genotipik ve fenotipik olarak tanımlanması. Mikrobiyol Bul 2011; 45: 478-88.

17. Yılmaz G, Çiftçioğlu A, Gündüz M, Özen M, Sarıcaoğlu EM, Akan H. Kandidemi saptanan hematolojik kanserli hastalarda etken dağılımı ve risk faktörlerinin değerlendirilmesi. Klimik Derg 2015; 28: 117-21.

18. Etiz P, Kibar F, Ekenoğlu Y, Yaman A. Kan kültürlerinden izole edilen Candida türlerinin dağılımının ve antifungal duyarlılıklarının retrospektif olarak değerlendirilmesi. ANKEM Derg 2015; 29: 105-13.

19. Montagna MT, Caggiano G, Lovero G, De Giglio O, Coretti C, Cuna T, Puntillo F. Epidemiology of invasive fungal infections in the intensive care unit: Results of a multicenter Italian survey (AURORA Project). Infection 2013; 41: 645-53.

20. Doi AM, Pignatari ACC, Edmond MB, Marra AR, Camargo LFA, Siqueira RA, Colombo AL. Epidemiology and microbiologic characterization of nosocomial candidemia from a Brazilian national surveillance program. PloS one 2016; 11: e0146909.

21. Atalay MA, Sav H, Demir G, Koç AN. Kan kültürlerinden izole edilen kandida türlerinin dağılımı ve amfoterisin $b$ ve flukonazol in vitro duyarlılıkları. Selçuk Tip Derg 2012; 28 : 149-51.

22. Sav H, Demir G, Atalay MA, Koç AN. Klinik örneklerden izole edilen Candida türlerinin değerlendirilmesi. Türk Hijyen ve Deneysel Biyoloji Derg 2013; 70: 175-80.

23. Lee MK, Williams LE, Warnock DW, Arthington-Skaggs BA. Drug resistance genes and trailing growth in Candida albicans isolates. J Antimicrob Chemother 2004; 53: 217-24.

24. Menezes EA, Vasconcelos Júnior AAD, Ângelo MRF, Cunha MDCDS, Cunha FA. Correlation between microdilution, $\mathrm{E}$ test, and disk diffusion methods for antifungal susceptibility testing of fluconazole against Candida sp. blood isolates. Rev Soc Bras Med Trop 2013; 46: 106-7.

25. Matar MJ, Ostrosky-Zeichner L, Paetznick VL, Rodriguez JR, Chen E, Rex JH. Correlation between E-test, disk diffusion, and microdilution methods for antifungal susceptibility testing of fluconazole and voriconazole. Antimicrob Agents Chem 2003; 47: 1647-51.

26. Pfaller MA, Espinel-Ingroff A, Boyken L, Hollis RJ, Kroeger J, Messer SA, Diekema DJ. Comparison of the broth microdilution (BMD) method of the European Committee on Antimicrobial Susceptibility Testing with the 24-hour CLSI BMD method for testing susceptibility of Candida species to fluconazole, posaconazole, and voriconazole by use of epidemiological cutoff values. J Clin Microbiol 2011; 49: 84550.

27. Arikan S, Gür D, Akova M. Comparison of E test, 
microdilution and colorimetric dilution with reference broth macrodilution method for antifungal susceptibility testing of clinically significant Candida species isolated from immunocompromised patients. Mycoses 1997; 40: 291-6.

28. Koç AN, Gökahmetoglu S, Oguzkaya M. Antifungal susceptibility testing of yeasts with broth microdilution and E-test methods. ANKEM Derg 1998; 12: 497-502.

29. Koç AN, Gökahmetoglu S, Oguzkaya M. Comparison of E test with the broth microdilution method in susceptibility testing of yeast isolates against four antifungals. Mycoses 2000; 43: 293-7.

30. Yücesoy $M$, Mutlu E, Yuluğ N. Antifungal duyarlılığın saptanmasında $\mathrm{E}$ test yönteminin değerlendirilmesi. ANKEM Derg 2001; 15: 670-7.

31. Evci C, Ener B, Göral G, Akçağlar S. Comparative evaluation of the antifungal susceptibility of Candida isolates from blood specimens: results of a study in a tertiary care hospital in Bursa, Turkey. Turk J Med Sci 2010; 40: 141-9.

32. Jaruvongvanich V. Correlation between broth microdilution, E-test and disk diffusion methods for testing antifungal susceptibility of Candida species isolated from Thai blood samples. Asian Biomed 2016; 75.

33. Barry AL, Pfaller MA, Rennie RP, Fuchs PC, Brown SD. Precision and accuracy of fluconazole susceptibility testing by broth microdilution, E test, and disk diffusion methods. Antimicrob Agents Chemother 2002; 46: 1781-4.

34. Maxwell MJ, Messer SA, Hollis RJ, Boyken L, Tendolkar S, Diekema DJ, International Fungal Surveillance Participant Group. Evaluation of $\mathrm{E}$ test method for determining fluconazole and voriconazole MICs for 279 clinical isolates of Candida species infrequently isolated from blood. J Clin Microbiol 2003; 41: 1087-90. 